\title{
Video Modelling, Drama Therapy and Self-help Skills of Pupils with Moderate Intellectual Disability in Lagos State, Nigeria
}

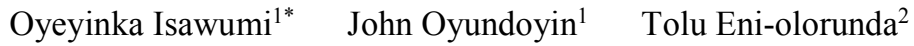 \\ 1.Department of Special Education, Faculty of Education, University of Ibadan, Ibadan \\ 2.Department of Home Science \& Management, College of Food Science \& Human Ecology, Federal University \\ of Agriculture, Abeokuta, Ogun
}

\begin{abstract}
The study examined the effects of Video Modelling (VM) and Drama Therapy (DM) on self-help skills of pupils with moderate intellectual disability in Lagos State, Nigeria using parental involvement and age of entry to school as moderating variables. The study adopted a pretest-posttest control group quasi experimental design using a sample size of Seventy-five (75) participants purposively selected from three special primary schools in Lagos State, Nigeria. The instrument used for the study include Slosson intelligence test $(\mathrm{r}=0.91)$, Pervasive Developmental Disorder (PDD) adaptive Skills test $(\mathrm{r}=0.81)$, Self-help skills performance test $(\mathrm{r}=0.76)$ and parental involvement rating scale( $\mathrm{r}=0.92)$. The findings revealed that $\mathrm{VM}$ and $\mathrm{DM}$ are effective in the acquisition and enhancement of self-help skills of pupils with moderate intellectual disability, also age of entry to school had significant main effect on self-help skills acquisition while parental involvement have none. Based on the findings in the study, some recommendations were made which includes Special Educator, Care-givers and teachers can utilize VM and DT to improve self-help skills of pupils with moderate intellectual disability irrespective of their parental involvement. Pupils with moderate intellectual disability should be encouraged to enrol for formal education early, this implies that participants that entered school early were known to do better in their self-help skills than those that entered school late. Curriculum planners should incorporate VM and DT in the curriculum for teaching pupils with moderate intellectual disability self-help skills.
\end{abstract}

Keywords: Self-help skills, Video modelling, Drama therapy, moderate intellectual disability

DOI: $10.7176 / \mathrm{JEP} / 12-9-05$

Publication date:March $31^{\text {st }} 2021$

\section{Introduction}

Children have a natural drive to be independent as they grow and mature which is a healthy part of normal child development. As children grow, they learn to do daily self-help tasks such as bathing, dressing and feeding with the initial support of their parents or caregivers until they are able to execute those tasks independently. Parents, teachers and caregivers help young children to become independent by encouraging them to take responsibility for their actions as far as possible. However, pupils with moderate intellectual disability (ID) manifest significant deficits in cognitive and adaptive skills which tend to hinder their ability to achieve complete independence. Consequently, pupils with moderate ID require specialised services to address their needs. Teachers are in search of effective strategies to facilitate the learning potentials especially self-help skills of these pupils with a view to helping them to become independent and functional members of their society.

Self-help skills, as home and community living techniques, enable one to deal with current and future day to day demands and responsibilities, thereby enabling children to learn to be independent and responsible. Specifically, these skills include but not limited to personal care and hygiene, clothing/dressing, laundry process, wearing and caring of shoes, food preparation and feeding, money management, transportation, job skills, home and kitchen management, time management, leisure and recreation (Friend, 2008). Singh, Agarwal and Singh (2012) pointed out that self-help skills can also be seen as the capability and the competency of a person to solve problems related to daily care routine such as dressing, grooming and meal time activities among others. Self-help skills considered in this research work include identification of self-care items and uses, eating skill, brushing of teeth skill and combined skills.

One of the most effective ways of teaching a skill is to demonstrate how the skill is performed. Modelling, which has been shown to be highly effective in many experimental studies, is a process by which a peer or an adult demonstrates the target behaviour to be imitated by the learner (National Autism Center, 2015). Modelling can either be live or video. In live modelling, the target behaviour is demonstrated in person by a model who then encourages the learners to repeat the particular behaviour, while in video modelling, the learners watch a video of the target behaviour being performed by a model and they are then given an opportunity to perform the same behaviour on their own (Bellini and Akullian, 2007; Corbett, 2003; Nicopoulos and Keenan, 2006). For the sake of emphasis and further clarification, video modelling is a teaching procedure that involves individuals viewing a videotaped sample of a model performing a specific, scripted activity or task. Having viewed the video-based model, the individuals are then directed to perform the activity or script they observed in the video (MacDonald, Clark, Garrigan, and Vangala, 2005). Video modelling is a visual teaching method that occurs by watching a video 
of someone modelling a targeted behaviour or skill and then initiating the behaviour/skill watched (Christos and Michael, 2014). The application of video modelling can be performed by anyone who participates in video recording (peer or adult) or observers as models (Nikopoulos and Keenan, 2006).

Another strategy that could be effective in teaching self-help skills to pupils with moderate ID is drama therapy. Drama therapy has the potential to foster pupils' active participation in the teaching and learning process thereby making learning memorable and evergreen in the mind of the pupils. This view was supported by Hough and Hough (2012) who opined that drama therapy provides a more productive path for education by promoting learners' active participation in the teaching and learning process. In other word, drama therapy entails the active role play of learners in the teaching and learning process. The concern of this present study, however, is how video modelling and drama therapy can be used to acquire and foster self-help skills (identification of self-care items and uses, eating skill, brushing of teeth skill and combined skills) of pupils with moderate ID.

\section{Hypothesis}

The following hypotheses were formulated and tested at 0.05 level of significance:

$\mathrm{Ho}_{1} \quad$ There is no significant main effect of treatments on self-help skills

$\mathrm{Ho}_{2}$ There is no significant main effect of parental involvement on self-help skills

$\mathrm{Ho}_{3} \quad$ There is no significant main effect of age of entry to school on self-help skills

$\mathrm{Ho}_{4}$ There is no significant interaction effect of treatments and parental involvement on self-help skills

$\mathrm{Ho}_{5}$ There is no significant interaction effect of treatments and age of entry to school on self-help skills

$\mathrm{Ho}_{6}$ There is no significant interaction effect of parental involvement and age of entry to school on self-help skills

$\mathrm{Ho}_{7} \quad$ There is no significant interaction effect of treatments, parental involvement and age of entry to school

\section{Methodology}

\section{Research design}

The study adopted a pretest-posttest control group quasi experimental design of a $3 \times 2 \times 2$ factorial matrix with treatment at three levels (video modelling, drama therapy and control group). This design was crossed at two levels with parental involvement (high or low) and age of entry to school (early or late) of pupils with moderate ID.

\section{Selection of participants}

The participants for the study consisted of pupils with moderate intellectual disability in special schools in Lagos State. The sample for the study consisted of Seventy-Five (75) participants that were selected from among the pupils with moderate intellectual disability in three selected special schools in Lagos State. These schools were purposively selected based on their population of pupils with intellectual disability (above 25 pupils with moderate intellectual disability) as well as the envisaged opportunity for different parental involvement (high or low).

\section{Instruments}

The following instruments were used in the study:

1. Slosson Intelligence Test - Revised (2005) $(r=0.91)$. This test was used to assess the intelligence quotient of the participants, screening for moderate ID.

2. PDD Adaptive Skills Test $(\mathrm{r}=0.81)$. This instrument was adopted to screen the participants in order to ascertain that the participants have deficits in self-help skills.

3. Self-Help Skills Performance Test (SHSPT) $(r=0.76)$. This instrument was developed by the researcher for the purpose of measuring self-help skills performance of children with moderate ID. The test is divided into four sections; A, B, C and D. Section A is based on demographic data, Section B consists of thirteen items that elicit information on identification of self-help items and it uses, Section $\mathrm{C}$ comprises of ten items that elicit information on eating skills of the participants and Section D consists of six items that elicit information on brushing skills of the participants.This instrument was trial tested with pupils with moderate intellectual disability from schools not included in the study scope to determine its reliability coefficient and it yielded a reliability coefficient of 0.76 .

4. Parental Involvement Rating Scale $(r=0.92)$. This scale was adapted by the researcher to measure the involvement of parent in their children's education especially the self- help skills acquisition of pupils living with moderate intellectual disability

\section{Treatment procedure}

Treatment was administered to the two experimental groups. Group one was treated with video modelling strategy while group two was treated with drama therapy. The third group, which is the control group was exposed to the conventional method of teaching used by classroom teachers. Treatment lasted for eight weeks (trice a week) with sessions of about 40 minutes on identification of self-help skills items and their uses, eating skills and brushing of teeth skills.

\section{Methods of data analysis}

The data collected was analysed using Analysis of Covariance (ANCOVA) to test the significance difference 
among several mean scores in the data. ANCOVA was used because it has the capacity to adjust the initial mean differences between the experimental groups and also takes care of interaction between independent variables and one or more co-variants; reduces the effect of extraneous variables in the pre-test and post-test measures. Furthermore, Sidak was used to trace the source(s) of significant main effect obtained. The seven null hypotheses were tested at 0.05 level of significant.

\section{Results and Discussion}

\subsection{Presentation of Results}

$\mathrm{Ho}_{1}$. There is no significant main effect of treatment on:

(a) Self -help skill (Identification of self-care items and their use of pupils with moderate ID)

Table 4.1a: Summary of Analysis of Covariance (ANCOVA) of identification of self-care items and its uses by Treatment (Video modelling, drama therapy and Conventional), parent involvement and age of entry

\begin{tabular}{|l|l|l|l|l|l|l|}
\hline Source & $\begin{array}{l}\text { Type III Sum } \\
\text { of Squares }\end{array}$ & df & $\begin{array}{l}\text { Mean } \\
\text { Square }\end{array}$ & F & Sig. & $\begin{array}{l}\text { Partial Eta } \\
\text { Squared }\end{array}$ \\
\hline Corrected Model & $2015.408 \mathrm{a}$ & 12 & 167.951 & 26.53 & 0.00 & 0.82 \\
\hline Intercept & 582.218 & 1 & 582.218 & 91.97 & 0.00 & 0.57 \\
\hline Pre-self-help & 358.912 & 1 & 358.912 & 56.69 & 0.00 & 0.45 \\
\hline Main effect & & & & & & \\
\hline Treatment & 665.268 & 2 & 332.634 & 52.54 & 0.00 & 0.60 \\
\hline Parent Involvement & 13.115 & 1 & 13.115 & 2.07 & 0.16 & 0.03 \\
\hline Age of entry & 108.396 & 1 & 108.396 & 17.12 & 0.00 & 0.20 \\
\hline 2-Way Interaction & & & & & & \\
\hline Treatment* Parent Involvement & 17.354 & 2 & 8.677 & 1.37 & 0.26 & 0.04 \\
\hline Treatment* Age of entry & 2.315 & 2 & 1.158 & 0.18 & 0.83 & 0.01 \\
\hline Parent Involvement * Age of entry & 0.07 & 1 & 0.07 & 0.01 & 0.92 & 0.00 \\
\hline 3-Way interaction & & & & & & \\
\hline $\begin{array}{l}\text { Treatment * Parent Involvement * } \\
\text { Age of entry }\end{array}$ & 5.466 & 2 & 2.733 & 0.43 & 0.65 & 0.01 \\
\hline Error & 443.146 & 70 & 6.331 & & & \\
\hline Total & 114023 & 83 & & & & \\
\hline Corrected Total & 2458.554 & 82 & & & & \\
\hline a R Squared = 820 (Adjusted R Squared & & & & & \\
\hline
\end{tabular}

Table 4.1 a shows the summary of analysis of covariance (ANCOVA) of student's post-test identification of self-care items and its uses by treatment (video modelling, drama therapy and Conventional), Parent involvement and age of entry. The table reveals that after adjusting for the covariance, (pre-test score in identification of selfcare items and its uses), the effect of treatment on student's identification of self-care items and its uses was statistically significant, $\mathrm{F}_{(2,70)}=52.54, \mathrm{p}<0.05$. Consequently, the null hypothesis which stated that there was no significant main effect of treatment on identification of self-care items and its uses was therefore rejected. The table further shows that the partial Eta square, $\left(\eta^{2}\right)$ was 0.6 , was considered to be sufficient effect size. The results of estimated marginal means and pairwise comparison of student's identification of self-care items and its uses are presented in Tables $4.1 \mathrm{~b}$ and $4.1 \mathrm{c}$.

Table 4.1b: Estimated Marginal Means of Students' identification of self-care items and its uses by Treatment (Video modelling, Drama therapy and Conventional)

\begin{tabular}{|l|l|l|l|l|}
\hline Treatment & Mean & Std. Error & $95 \%$ Confidence Interval & \\
\hline & & & Lower Bound & Upper Bound \\
\hline Video modelling & $39.06 \mathrm{a}$ & 0.982 & 37.104 & 41.023 \\
\hline Drama therapy & $39.13 \mathrm{a}$ & 0.569 & 37.992 & 40.26 \\
\hline Control & $31.72 \mathrm{a}$ & 0.561 & 30.601 & 32.839 \\
\hline
\end{tabular}

a Covariates appearing in the model are evaluated at the following values: pre-Identification of self-care items and its uses $=31.12$. 
Table 4.1c: Pairwise Comparison of Students' identification of self-care items and its uses by Treatment (Video modelling, Drama therapy and Conventional)

\begin{tabular}{|c|c|c|c|c|c|c|}
\hline $\begin{array}{l}\text { (I) } \\
\text { Treatment }\end{array}$ & $\begin{array}{l}(\mathrm{J}) \\
\text { Treatment }\end{array}$ & $\begin{array}{l}\text { Mean Difference } \\
\text { (I-J) }\end{array}$ & $\begin{array}{l}\text { Std. } \\
\text { Error }\end{array}$ & Sig. & $\begin{array}{l}95 \% \quad \text { Confidence } \\
\text { Interval for Difference }\end{array}$ & \\
\hline & & & & & Lower Bound & Upper Bound \\
\hline \multirow[t]{2}{*}{ Video } & Drama & -0.062 & 1.188 & 1.00 & -2.968 & 2.844 \\
\hline & Control & $7.344 *$ & 1.154 & 0.00 & 4.521 & 10.167 \\
\hline \multirow[t]{2}{*}{ Drama } & Video & 0.062 & 1.188 & 1.00 & -2.844 & 2.968 \\
\hline & Control & $7.406^{*}$ & 0.776 & 0.00 & 5.507 & 9.304 \\
\hline \multirow[t]{2}{*}{ Control } & Video & $-7.344^{*}$ & 1.154 & 0.00 & -10.167 & -4.521 \\
\hline & Drama & $-7.406^{*}$ & 0.776 & 0.00 & -9.304 & -5.507 \\
\hline \multicolumn{7}{|c|}{ Based on estimated marginal means } \\
\hline \multicolumn{7}{|c|}{ * The mean difference is significant at the 0.05 level } \\
\hline \multicolumn{7}{|c|}{ b Adjustment for multiple comparisons: Sidak } \\
\hline
\end{tabular}

Table 4.1b further reveals that Experimental Group II (Drama therapy) has the highest mean score $\bar{x}=39.13$ followed by participants in Experimental Group I (Video modelling) with the mean score $\bar{x}=39.06$ followed by the participants in and control group (conventional) had the least mean score $\bar{x}=31.72$. Table $4.1 \mathrm{c}$ confirmed that the difference between experimental group I (Video modelling) and Control group (Conventional) together with the difference between Experimental Group II (Drama therapy) and control group (conventional) were statistically significant.

(b) Eating skill of pupils with moderate ID

Table 4.2a: Summary of Analysis of Covariance (ANCOVA) of Self-help skill-Eating skills by Treatment (Video modelling, drama therapy and Control), parent involvement and age of entry.

\begin{tabular}{|l|l|l|l|l|l|l|}
\hline Source & $\begin{array}{l}\text { Type III Sum } \\
\text { of Squares }\end{array}$ & df & $\begin{array}{l}\text { Mean } \\
\text { Square }\end{array}$ & F & Sig. & $\begin{array}{l}\text { Partial Eta } \\
\text { Squared }\end{array}$ \\
\hline Corrected Model & $1771.96 \mathrm{a}$ & 12 & 147.66 & 40.19 & 0.00 & 0.87 \\
\hline Intercept & 321.39 & 1 & 321.39 & 87.47 & 0.00 & 0.56 \\
\hline Pre-Test self help & 225.25 & 1 & 225.25 & 61.31 & 0.00 & 0.47 \\
\hline Main Effect & & & & & & \\
\hline Treatment & 448.62 & 2 & 224.31 & 61.05 & 0.00 & 0.64 \\
\hline Parent Involvement & 0.28 & 1 & 0.28 & 0.08 & 0.78 & 0.00 \\
\hline Age of entry & 9.51 & 1 & 9.51 & 2.59 & 0.11 & 0.04 \\
\hline 2-Way Interaction & & & & & & \\
\hline Treatment* Parent Involvement & 11.31 & 2 & 5.65 & 1.54 & 0.22 & 0.04 \\
\hline Treatment* Age of entry & 19.67 & 2 & 9.84 & 2.68 & 0.08 & 0.07 \\
\hline Parent Involvement * Age of entry & 5.29 & 1 & 5.29 & 1.44 & 0.23 & 0.02 \\
\hline 3-Way Interaction & & & & & & \\
\hline Treatment * Parent Involvement* Age of entry & 0.07 & 2 & 0.03 & 0.01 & 0.991 & 0.00 \\
\hline Error & 257.19 & 70 & 3.67 & & & \\
\hline Total & 59708 & 83 & & & & \\
\hline Corrected Total & 2029.16 & 82 & & & & \\
\hline a R Squared =0.873 (Adjusted R Squared =0.852) & & & & \\
\hline
\end{tabular}

Table 4.2a shows the summary of analysis of covariance (ANCOVA) of student's post-test Self-help skillEating skills by treatment (video modelling, drama therapy and Control), Parent involvement and age of entry. The table reveals that after adjusting for the covariance, (pre- test score in Self-help skill-Eating skills), the effect of treatment on student's Self-help skill-Eating skills was statistically significant, $\mathrm{F}_{(2,70)}=61.05, \mathrm{p}<0.05$. Consequently, the null hypothesis which stated that there was no significant main effect of treatment on Self-help skill-Eating skills was therefore rejected. The table further shows that the partial Eta square, $\left(\eta^{2}\right)$ was 0.64 , was considered to be sufficient effect size according to $\left(\eta^{2}\right)$. The results of estimated marginal means and pairwise comparison of student's Self-help skill-Eating skills are presented in Tables 4.2b and 4.2.1c. 
Table 4.2b: Estimated Marginal Means of Students' Self-help skill-Eating skills by Treatment (Video modelling, Drama therapy and Control)

\begin{tabular}{|l|l|l|l|l|}
\hline Treatment & Mean & Std. Error & $95 \%$ Confidence Interval & \\
\hline & & & Lower Bound & Upper Bound \\
\hline Video modelling & $28.04 \mathrm{a}$ & 0.714 & 26.611 & 29.46 \\
\hline Drama therapy & $28.45 \mathrm{a}$ & 0.426 & 27.596 & 29.295 \\
\hline $\begin{array}{l}\text { Control } \\
\text { a Covariates appearing in the model are evaluated at the following values: pre self-help skills eating skills }= \\
\text { 22.58. }\end{array}$ 22.02a & 0.427 & 21.17 & 22.875 \\
\hline
\end{tabular}

Table 4.2c: Pairwise Comparison of Students' Self-help skill-Eating skills by

Treatment (Video modelling, Drama therapy and Control)

\begin{tabular}{|c|c|c|c|c|c|c|}
\hline $\begin{array}{l}\text { (I) } \\
\text { Treatment }\end{array}$ & $\begin{array}{l}\mathrm{J}) \\
\text { Treatment }\end{array}$ & $\begin{array}{l}\text { Mean Difference } \\
(\mathrm{I}-\mathrm{J})\end{array}$ & $\begin{array}{l}\text { Std. } \\
\text { Error }\end{array}$ & Sig.b & $\begin{array}{ll}95 \% & \text { Confidence } \\
\text { Interval for Differenceb }\end{array}$ & \\
\hline & & & & & Lower Bound & $\begin{array}{l}\text { Upper } \\
\text { Bound }\end{array}$ \\
\hline \multirow[t]{2}{*}{ Video } & Drama & -0.41 & 0.84 & 0.95 & -2.459 & 1.638 \\
\hline & Control & $6.01 *$ & 0.83 & 0.00 & 3.983 & 8.042 \\
\hline \multirow[t]{2}{*}{ Drama } & Video & 0.41 & 0.84 & 0.95 & -1.638 & 2.459 \\
\hline & Control & $6.42 *$ & 0.62 & 0.00 & 4.911 & 7.935 \\
\hline \multirow[t]{2}{*}{ Control } & Video & $-6.01 *$ & 0.83 & 0.00 & -8.042 & -3.983 \\
\hline & Drama & $-6.42 *$ & 0.62 & 0.00 & -7.935 & -4.911 \\
\hline \multicolumn{7}{|c|}{ Based on estimated marginal means } \\
\hline \multicolumn{7}{|c|}{ * The mean difference is significant at the .05 level. } \\
\hline \multicolumn{7}{|c|}{ b Adjustment for multiple comparisons: Sidak. } \\
\hline
\end{tabular}

Table 4.2b further reveals that Experimental Group II (Drama therapy) has the highest mean score $\bar{x}=28.45$ followed by participants in Experimental Group I (Video modelling) with the mean score $\bar{x}=28.04$ followed by the participants in and control group (Control) had the least mean score $\bar{x}=22.02$. Table 4.2c confirmed that the difference between experimental group I (Video modelling) and Control group (Control) together with the difference between Experimental Group II (Drama therapy) and control group (Control) were statistically significant.

(c) Brushing of teeth skill of pupils with moderate ID

Table 4.3a:Summary of Analysis of Covariance (ANCOVA) of brushing of the teeth skills by Treatment (Video modelling, drama therapy and Conventional), parent involvement and age of entry

\begin{tabular}{|l|l|l|l|l|l|l|}
\hline Source & $\begin{array}{l}\text { Type III Sum } \\
\text { of Squares }\end{array}$ & df & $\begin{array}{l}\text { Mean } \\
\text { Square }\end{array}$ & F & Sig. & $\begin{array}{l}\text { Squartial Eta } \\
\text { Squared }\end{array}$ \\
\hline Corrected Model & $610.102^{\mathrm{a}}$ & 12 & 50.842 & 28.13 & 0.00 & 0.83 \\
\hline Intercept & 189.012 & 1 & 189.012 & 104.59 & 0.00 & 0.59 \\
\hline Pre Brushing Skill & 62.292 & 1 & 62.292 & 34.47 & 0.00 & 0.33 \\
\hline Main effect & & & & & & \\
\hline Treatment & 194.027 & 2 & 97.013 & 53.68 & 0.00 & 0.61 \\
\hline Parent Involvement & 0.317 & 1 & .317 & 0.18 & 0.68 & 0.00 \\
\hline Age of entry & 13.442 & 1 & 13.442 & 7.44 & 0.01 & 0.10 \\
\hline 2-Way Interaction & & & & & & \\
\hline Treatment* Parent_Involvement & 0.717 & 2 & .358 & 0.20 & 0.82 & 0.01 \\
\hline Treatment* Age_of_entry & 9.889 & 2 & 4.944 & 2.74 & 0.07 & 0.07 \\
\hline Parent Involvement* Age_of_entry & 0.833 & 1 & .833 & 0.46 & 0.50 & 0.01 \\
\hline 3-Way interaction & & & & & & \\
\hline $\begin{array}{l}\text { Treatment * Parent_Involvement } * \\
\text { Age_of_entry }\end{array}$ & 1.016 & 2 & 0.508 & 0.28 & 0.76 & 0.01 \\
\hline Error & 126.500 & 70 & 1.807 & & & \\
\hline Total & 23218.000 & 83 & & & & \\
\hline Corrected Total & 736.602 & 82 & & & & \\
\hline a R Squared =.828 (Adjusted R Squared $=.799)$ & & & \\
\hline
\end{tabular}


Table 4.3a shows the summary of analysis of covariance (ANCOVA) of student's post-test brushing of the teeth skills by treatment (video modelling, drama therapy and Conventional), Parent involvement and age of entry. The table reveals that after adjusting for the covariance, (pre- test score in brushing of the teeth skills), the effect of treatment on student's brushing of the teeth skills was statistically significant, $\mathrm{F}_{(2,70)}=53.68, \mathrm{p}<0.05$. Consequently, the null hypothesis which stated that there was no significant main effect of treatment on brushing of the teeth skills was therefore rejected. The table further shows that the partial Eta square, $\left(\eta^{2}\right)$ was 0.61 , was considered to be sufficient effect size according to $\left(\eta^{2}\right)$. The results of estimated marginal means and pairwise comparison of student's brushing of the teeth skills are presented in Tables $4.3 \mathrm{~b}$ and $4.3 \mathrm{c}$.

Table 4.3b: Estimated Marginal Means of Students' brushing of the teeth skills by Treatment (Video modelling, Drama therapy and Conventional)

\begin{tabular}{|l|l|l|l|l|}
\hline Treatment & Mean & Std. Error & $95 \%$ Confidence Interval & \\
\hline & & & Lower Bound & Upper Bound \\
\hline Video modelling & $18.400^{\mathrm{a}}$ & .501 & 17.401 & 19.398 \\
\hline Drama therapy & $17.640^{\mathrm{a}}$ & .285 & 17.072 & 18.208 \\
\hline Control & $13.861^{\mathrm{a}}$ & .298 & 13.266 & 14.456 \\
\hline
\end{tabular}

a Covariates appearing in the model are evaluated at the following values: pre- brushing of the teeth skills $=$ 13.55 .

Table 4.3c: Pairwise Comparison of Students' brushing of the teeth skills by Treatment (Video modelling, Drama therapy and Conventional)

\begin{tabular}{|c|c|c|c|c|c|c|}
\hline $\begin{array}{l}\text { (I) } \\
\text { Treatment }\end{array}$ & $\begin{array}{l}\text { (J) } \\
\text { Treatment }\end{array}$ & $\begin{array}{l}\text { Mean Difference } \\
(\mathrm{I}-\mathrm{J})\end{array}$ & $\begin{array}{l}\text { Std. } \\
\text { Error }\end{array}$ & Sig. & $\begin{array}{l}95 \% \quad \text { Confidence } \\
\text { Interval for Difference }\end{array}$ & \\
\hline & & & & & Lower Bound & $\begin{array}{l}\text { Upper } \\
\text { Bound }\end{array}$ \\
\hline Video & Drama & 0.760 & 0.577 & 0.473 & -0.652 & 2.171 \\
\hline & Control & $4.538^{*}$ & 0.584 & 0.000 & 3.110 & 5.967 \\
\hline Drama & Video & -0.760 & 0.577 & 0.473 & -2.171 & 0.652 \\
\hline & Control & $3.779^{*}$ & 0.410 & 0.000 & 2.777 & 4.781 \\
\hline Control & Video & $-4.538^{*}$ & 0.584 & 0.000 & -5.967 & -3.110 \\
\hline & Drama & $-3.779^{*}$ & 0.410 & 0.000 & -4.781 & -2.777 \\
\hline \multicolumn{7}{|c|}{ Based on estimated marginal means } \\
\hline \multicolumn{7}{|c|}{$*$ The mean difference is significant at the 0.05 level } \\
\hline \multicolumn{7}{|c|}{ b Adjustment for multiple comparisons: Sidak } \\
\hline
\end{tabular}

Table 4.3b further reveals that Experimental Group I (Video therapy) has the highest mean score $\bar{x}=18.40$ followed by participants in Experimental Group II (Drama modelling) with the mean score $\bar{x}=17.64$ followed by the participants in and control group (conventional) had the least mean score $\bar{x}=13.86$. Table $4.3 \mathrm{c}$ confirmed that the difference between experimental group I (Video modelling) and Control group (Conventional) together with the difference between Experimental Group II (Drama therapy) and control group (conventional) were statistically significant. The estimated marginal mean score was further shown in Figure 4.3a 
(d) Combined skills of pupils with moderate ID

Table 4.4a: Summary of Analysis of Covariance (ANCOVA) of combined skills by Treatment (Video modelling, drama therapy and Conventional), parent involvement and age of entry

\begin{tabular}{|l|l|l|l|l|l|l|}
\hline Source & $\begin{array}{l}\text { Type III Sum } \\
\text { of Squares }\end{array}$ & df & $\begin{array}{l}\text { Mean } \\
\text { Square }\end{array}$ & F & Sig. & $\begin{array}{l}\text { Partial Eta } \\
\text { Squared }\end{array}$ \\
\hline Corrected Model & $11811.409^{\mathrm{a}}$ & 12 & 984.284 & 46.70 & 0.000 & 0.89 \\
\hline Intercept & 1427.623 & 1 & 1427.623 & 67.74 & 0.000 & 0.49 \\
\hline Pre Brushing Skill & 1478.301 & 1 & 1478.301 & 70.14 & 0.000 & 0.50 \\
\hline Main effect & & & & & & \\
\hline Treatment & 3718.663 & 2 & 1859.331 & 88.22 & 0.000 & 0.72 \\
\hline Parent Involvement & 10.920 & 1 & 10.920 & 0.52 & 0.47 & 0.01 \\
\hline Age of entry & 239.458 & 1 & 239.458 & 11.36 & 0.001 & 0.14 \\
\hline 2-Way Interaction & & & & & & \\
\hline Treatment* Parent_Involvement & 60.426 & 2 & 30.213 & 1.43 & 0.25 & 0.04 \\
\hline Treatment* Age_of_entry & 13.242 & 2 & 6.621 & 0.31 & 0.73 & 0.01 \\
\hline Parent_Involvement* Age_of_entry & 10.593 & 1 & 10.593 & 0.50 & 0.48 & 0.01 \\
\hline 3-Way interaction & & & & & & \\
\hline $\begin{array}{l}\text { Treatment * Parent_Involvement * } \\
\text { Age_of_entry }\end{array}$ & 6.864 & 2 & 3.432 & 0.16 & 0.85 & 0.01 \\
\hline Error & 1475.313 & 70 & 21.076 & & & \\
\hline Total & 537629.000 & 83 & & & & \\
\hline Corrected Total & 13286.723 & 82 & & & & \\
\hline a R Squared =.889 (Adjusted R Squared $=.870)$ & & & & & \\
\hline
\end{tabular}

Table 4.4a shows the summary of analysis of covariance (ANCOVA) of student's post-test combined skills by treatment (video modelling, drama therapy and Conventional), Parent involvement and age of entry. The table reveals that after adjusting for the covariance, (pre-test score in combined skills), the effect of treatment on student's combined skills was statistically significant, $\mathrm{F}_{(2,70)}=88.22, \mathrm{p}<0.05$. Consequently, the null hypothesis which stated that there was no significant main effect of treatment on combined skills was therefore rejected. The table further shows that the partial Eta square, $\left(\eta^{2}\right)$ was 0.72 , was considered to be sufficient effect size according to $\left(\eta^{2}\right)$. The results of estimated marginal means and pairwise comparison of student's combined skills are presented in Tables $4.4 \mathrm{~b}$ and $4.4 \mathrm{c}$.

Table 4.4b: Estimated Marginal Means of Students' combined skills by Treatment (Video modelling, Drama therapy and Conventional)

\begin{tabular}{|l|l|l|l|l|}
\hline Treatment & Mean & Std. Error & 95\% Confidence Interval & \\
\hline & & & Lower Bound & Upper Bound \\
\hline Video modelling & 85.91 & 1.747 & 82.426 & 89.393 \\
\hline Drama therapy & 84.76 & 1.043 & 82.679 & 86.839 \\
\hline Control & 67.50 & 1.013 & 65.481 & 69.522 \\
\hline Cool
\end{tabular}

a Covariates appearing in the model are evaluated at the following values: pre-Combined skills $=67.25$.

Table 4.4c: Pairwise Comparison of Students' combined skills by

Treatment (Video modelling, Drama therapy and Conventional)

\begin{tabular}{|c|c|c|c|c|c|c|}
\hline $\begin{array}{l}\text { (I) } \\
\text { Treatment }\end{array}$ & $\begin{array}{l}\text { (J) } \\
\text { Treatment }\end{array}$ & $\begin{array}{l}\text { Mean Difference } \\
\text { (I-J) }\end{array}$ & $\begin{array}{l}\text { Std. } \\
\text { Error }\end{array}$ & Sig. & $\begin{array}{l}95 \% \\
\text { Interval for Difference }\end{array}$ & \\
\hline & & & & & Lower Bound & $\begin{array}{l}\text { Upper } \\
\text { Bound }\end{array}$ \\
\hline Video & Drama & 1.151 & 2.103 & 0.929 & -3.994 & 6.295 \\
\hline & Control & $18.408^{*}$ & 2.029 & 0.000 & 13.445 & 23.370 \\
\hline Drama & Video & -1.151 & 2.103 & 0.929 & -6.295 & 3.994 \\
\hline & Control & $17.257^{*}$ & 1.439 & 0.000 & 13.736 & 20.778 \\
\hline Control & Video & $-18.408^{*}$ & 2.029 & 0.000 & -23.370 & -13.445 \\
\hline & Drama & $-17.257^{*}$ & 1.439 & 0.000 & -20.778 & -13.736 \\
\hline \multicolumn{7}{|c|}{ Based on estimated marginal means } \\
\hline * The $m$ & $\begin{array}{l}\text { ifference is } \\
\text { for multin }\end{array}$ & gnificant at the & level & & & \\
\hline
\end{tabular}

Table 4.4b further reveals that Experimental Group I (Video therapy) has the highest mean score $\bar{x}=85.91$ followed by participants in Experimental Group II (Drama modelling) with the mean score $\bar{x}=84.76$ followed by 
the participants in and control group (conventional) had the least mean score $\bar{x}=67.50$. Table 4.4.1c confirmed that the difference between experimental group I (Video modelling) and Control group (Conventional) together with the difference between Experimental Group II (Drama therapy) and control group (conventional) were statistically significant.

\subsection{Summary of findings}

The findings of this study are summarised as follows:

1. The main effect of treatment on self-help skills (identification of self-care items and their use, eating skills, brushing of teeth skills and combined skills) was significant.

2. There was no significant main effect of parental involvement on self-help skills (identification of selfcare items and their use, eating skills, brushing of teeth skills and combined skills) of pupils with moderate ID.

3. There was significant main effect of age of entry to school on identification of self-care items and their use, brushing of teeth skills and combined skills but there is no significant main effect of age of entry to school on eating skills of pupils with moderate ID.

4. There was no significant interaction effect of treatment and parental involvement on self-help skills (identification of self-care items and their use, eating skills and brushing of teeth skills) of pupils with moderate ID.

5. The interaction effect of treatment and age of entry to school on self-help skills (identification of selfcare items and their use, eating skills and brushing of teeth skills) of pupils with moderate ID was not significant.

6. There was no significant interaction effect of parental involvement and age of entry to school on self-help skills (identification of self-care items and their use, eating skills and brushing of teeth skills) of pupils with moderate ID.

7. The three-way interaction effect of treatment, parental involvement and age of entry to school on selfhelp skills (identification of self-care items and their use, eating skills and brushing of teeth skills) of pupils with moderate ID was not significant.

\section{Conclusion}

The study focused on self-help skills of pupils with moderate intellectual disability in Lagos, Nigeria. Parental involvement (at two levels-high and low) and age of entry to school (at two levels-early and late) were the moderating variables considered in the study. Participants in this study were assigned to three groups; two experimental groups (exposed to video modelling and drama therapy) and a control group. Relevant data were collected and analysed. Based on the findings of this study, it was concluded that both video modelling and drama therapy were effective in enhancing the self-help skills of participants.

Finding from this study established that the treatment effectively enhanced the self-help skills of the participants; drama therapy enhanced self-help skills of participants more when compared to video modelling. Their age of entry to school as a moderating variable has effect on identification of self-care items and their use, brushing of teeth skills and combined skills but did not moderate eating skills of pupils with moderate ID. The main effect of parental involvement on self-help skills (identification of self-care items and their use, eating skills, brushing of teeth skills and combined skills) of pupils with moderate ID was not significant. The interaction between treatment and parental involvement, treatment and age of entry as well as treatment, parental involvement and age of entry had insignificant effect on the self-help skills of pupils with moderate intellectual disability.

\section{Educational implications of the findings}

The results of this study have several educational implications. This study has proven that video modelling and drama therapy are effective strategies for enhancing self-help skills of participants which imply that self-help skills can be effectively enhanced using the strategies among participants. Special educators should endeavour to utilise these strategies in providing instruction to pupils with moderate intellectual disability to enhance their self-help skills.

Parental involvement had no significant main effect on self-help skills. This implies that irrespective of parental involvement (high and low) will not interfere in the self-help skills. The knowledge of this will hopefully assist educators in appreciating the non-interference of parental involvement on the self-help skills of pupils with moderate intellectual disability. Age of entry to school had significant main effect on self-help skills, which implies that participants that entered school early were known to do better in their self-help skills than those that entered school late.

Furthermore, treatment, parental involvement and age of entry to school interaction was not significant on self-help skills. In essence, when utilising video modelling and drama therapy strategies on self-help skills for pupils with moderate intellectual disability, it is important that the educator ensure that all materials and 
experiences are adequately provided. This experience should be such that all pupils with moderate intellectual can benefit from irrespective of parental involvement.

\section{Recommendations}

The following were the recommendations made based on the findings of the study and the conclusion drawn thereof:

1. Special Educator, Care-givers and teachers should use video modelling and drama therapy to teach selfhelp skills to pupils with moderate ID.

2. Drama therapy can be used effectively to teach pupils with moderate ID identifications of self-care items and eating skills while video modelling is effective for teaching brushing of teeth skills.

3. Pupils with moderate intellectual disability should be encouraged to enrol for formal education early, especially between ages $6-10$ years as revealed in the study.

4. Curriculum planners should incorporate video modelling and drama therapy in the curriculum for pupils with moderate ID. This will help curtail the use of teaching strategies that are ineffective for the development of self-help skills in pupils with ID.

5. Parents and teachers of pupils with moderate intellectual disability should source for video modelling materials and learn drama therapy for the purpose for self-help skills development.

6. Associations of special educators should organise trainings and seminars for special educators to raise awareness on the effectiveness of video modelling and drama therapy in enhancing self-help skills of pupils with moderate ID.

\section{References}

Bellini, S. and Akullian, J. (2007). A Meta-analysis of video modeling and video self-modeling interventions for children and adolescents with autism spectrum disorder. Exceptional Children, 73, 264-287.

Christos, K. N. and Michael K., 2014. Watch me learn. Journal of Applied Behaviour Analysis 37 (1): 93-96.

Corbett, B. A. (2003). Video modeling: A window into the world of autism. The Behavior Analyst Today, 4, 367

Friend, M. 2008. Special Education Contemporary Perspectives for School Professionals. (2nd Ed). USA: Pearson Education Inc. Company.

Hough, B.H. and Hough, S. 2012. The Play Was Always the Thing: Drama's Effect on Brain Function. Psychology; 3(6): 454-456.

MacDonald, R., Clark, M., Garrigan, E., and Vangala, M. 2005. Using video modeling to teach pretend play to children with autism. Behavioral Intervention, 20, 225-238.

National Autism Center (2015). Findings and conclusions: National standards project, phase 2

Nikopoulos, C. K., and Keeanan, M. 2006. Video modeling and behaviour analysis: A guide for teaching social skills to children with autism. London, UK: Jessica Kingsley Publishers

Singh, A., Agarwal, A. and Singh, P.L. 2012. Remediating Self-help skill Deficits of Mentally Retarded Children through Computer Aided Instruction. BRICS Journal of Educational Research 2 (3) 